\title{
THE BIOLOGICAL BASES OF ATTACHMENT
}

\section{Paula Oliveira}

University College London

\section{Pasco Fearon}

University College London

From its origins, human attachment has always been viewed as a primary, biologically-based phenomenon with strong evolutionary roots. The last few decades have seen large increase in research studies from developmental science and neighbouring disciplines that attest the role of biology in attachment processes. This review aims to provide a concise and up to date summary of research on the biological bases of attachment throughout the lifespan. We will review the role of genetics, physiology—focusing on oxytocin and cortisol—and brain mechanisms that underlie attachment behaviour and its consequences. Findings are complex in that they often don't apply equally to all patterns of attachment, to all ages, or all temperament styles, amongst other factors. In addition, some important evidence is indirect, coming from studies that investigate the impact of variations in caregiving quality —including maltreatment and separation from caregiving figures — on biology, and vice-versa, rather than looking at differences in attachment per se, which complicates their interpretation. Implications for practice are raised throughout.

\section{Keywords}

Attachment, genetics, brain development, oxytocin, cortisol, maltreatment, foster care, institutional care. 
Corresponding author:

Paula Oliveira, University College London, Research Department of Clinical, Educational and Health Psychology, 1-19 Torrington Place, London WC1E 7HB

Email: paula.oliveira@ucl.ac.uk

\section{Introduction}

Children develop attachments for reasons thought to be deeply rooted in evolution, to ensure the parental care required for their safety and healthy development. When developing attachment theory, Bowlby was deeply influenced not only by his own experience in working with delinquent and homeless children, but also by scientific studies of caregiving in animals which provided strong evidence for the evolutionary roots of attachment (Bowlby, 1969, 1973, 1980) and helped make sense of its basic purpose -to promote survival. According to Bowlby, attachment represents a primary, biologically-based motivational system, selected through evolution to promote survival through maintenance of proximity to a primary caregiver(s) (see Fraley, Brumbaugh, \& Marks, 2005; Simpson \& Belsky, 2008). Thus, although we think of attachments and of attachment behaviour as highly social phenomena, they are also profoundly biological.

Developmental researchers have identified several distinct patterns of attachment, which appear to represent differences in how well a child is able to use their caregiver as a source of comfort when distressed or worried. The so-called secure type is observed in the well-known Strange Situation Procedure when a child misses the caregiver when absent, and seeks contact and comfort, which is effective, when they return. In the avoidant pattern, young children actively avoid contact with the caregiver when they return, whereas the resistant pattern is marked by heightened anxiety even before the caregiver leaves, and anger and 
extensive distress when reunited. Disorganised attachment is a form of attachment in which the child appears to lack a coherent strategy for dealing with the stress of separation, and may become disoriented, frozen, or overtly fearful. These three non-secure forms of attachment, and particularly disorganised attachment, are thought to represent a relationship-based vulnerability to future stressors and to poorer social and emotional adjustment. These types of early attachment are observed relatively commonly and in circumstances where the parentchild relationship has not been severely disrupted. In more extreme circumstances, such as exposure to institutional rearing, repeated changes in primary caregivers or severe social neglect, two types of disturbed attachment behaviour have been described (e.g., Oosterman \& Schuengel, 2008; Smyke, Dumitrescu, \& Zeanah, 2002). One is a disinhibited pattern, characterised by indiscriminate social approach and lack of wariness of strangers - captured in the diagnostic category Disinhibited Social Engagement Disorder (DSED; American Psychiatric Association, 2013). The other is an inhibited pattern, characterised by extreme social withdrawal, lack of comfort seeking from, and emotional reciprocity with available caregivers - reflected in the diagnostic category Reactive Attachment Disorder (RAD; American Psychiatric Association, 2013). The key distinction between disorganised attachment and attachment disorders (DSED or RAD) is that while disorganisation is seen as conferring increased risk for maladjusted developmental trajectories including psychopathology, DSED and RAD are shown pervasively across relationships and situations and are considered an indication of psychopathology themselves (Boris \& Zeanah, 1999; Gleason et al., 2011; Rutter, Kreppner, \& Sonuga-Barke, 2009). These conceptual distinctions are important for understanding the findings reviewed in this paper. In addition, as we will see throughout this review, evidence suggests that the role of biology is not the same across all aspects or patterns of attachment. 
When we look at the biology of children's attachments in contemporary research, we can see several themes. The first is the role of biology in causing differences between children in their attachment behaviour - particularly the role of genetics and the role of sensitive periods in brain development. Another important theme in the literature on the biology of attachment concerns physiology — for example understanding how attachment security or insecurity may affect a child's physiological responsiveness to stress. A final area of great interest is in understanding the brain mechanisms that underlie attachment behaviour and its consequences. The aim of this review is to provide a concise and up to date summary of research on each of these topics.

\section{Genetics}

Questions about the environmental versus genetic causes of attachment security and insecurity originally centred on the role of temperament (for a review, see Vaughn, Bost, \& van IJzendoorn, 2008). The data regarding temperamental influences on attachment are mixed. For example, despite the fact that some studies have found associations between high levels of behavioural inhibition in early infancy and resistant attachment (Kagan, Snidman, Arcus, \& Reznick, 1994), and between irritability and the avoidant classification (van den Boom, 1994), other studies have found no associations between temperament and attachment classification (Belsky, 1996; Goldsmith \& Alansky, 1987). Other studies have found that attachment might be explained by interactions between temperament and maternal personality (Mangelsdorf, Gunnar, Kestenbaum, Lang, \& Andreas, 1990) or maternal lack of social support (Crockenberg, 1981). In the most comprehensive review conducted to date, Groh and colleagues (2017) found that, across 109 studies including over 11,000 children, the 
association between attachment insecurity (specifically avoidant and disorganised attachment) and temperament was equivalent to an effect size of $d=.10$, which is very small (one tenth of a standard deviation difference). However, there was a moderate association between temperament and resistant attachment, equivalent to an effect size of $d=.30$. Thus, temperament appears to play a very limited role in attachment security generally and disorganised and avoidant attachment, but may play some more significant role in resistant attachment. However, it is crucial to note that temperament is itself influenced by both genetic and environmental factors, so even when studies do find associations between temperament and attachment this cannot be straightforwardly attributed to biological causes (van IJzendoorn \& Bakermans-Kranenburg, 2012). The only way to test directly whether genes play a role in the differences we observed in children's attachments is through the use of behavioural-genetic studies, such as twin and adoption studies. These studies work by looking for similarities between different traits or behaviours between related individuals and seeing whether that varies depending on how genetically similar they are. For example, monozygotic (MZ) twins are genetically identical, whereas dizygotic (DZ) twins share only $50 \%$ of their genes, so when MZ twins are more similar to each other on a trait than DZ twins, this indicates, if one accepts certain assumptions, genetic influence. The results of behavioural genetic studies of very young children have been quite remarkable. Twin studies (e.g., Fearon et al., 2006; O’Connor \& Croft, 2001; Roisman \& Fraley, 2008) have produced consistent evidence that the environment — and particularly environments that make twins and siblings similar to each other (known as the shared environment)—plays a preeminent role in the development of individual differences in attachment security. Indeed, in those studies the shared environment was estimated to account for $32-53 \%$ of the variance in attachment security and the non-shared environment (environmental influences that make 
children in the same family different from each other) $36-53 \%$, while the effect of genes was minimal and non-significant.

Despite the fact that twin studies indicated minimal genetic influence on attachment outcomes, there is a large body of work looking directly at DNA to see whether specific genes might be associated with attachment security and disorganisation. These studies have generally used what is called the "candidate gene" approach, in which specific genes are selected a priori based on biological arguments about the plausibility of their possible association with a particular trait or behaviour. These studies have looked at differences between individuals in the DNA code within a particular gene, and tested whether these genetic "variants" are associated with different patterns of attachment. In other words, is a given attachment pattern associated with the "variants" of the candidate gene that individuals carry? However, these studies have tended to produce some initially exciting findings that then could not be replicated, much like other fields in behavioural science and psychiatry. In one landmark study, initial evidence was found of an association between a certain variant of the gene that produces the dopamine D4 receptor-which affects how efficiently dopamine is transmitted in the brain — and disorganised attachment (Lakatos et al., 2002, 2000). However, this association failed to be replicated in several subsequent studies (see BakermansKranenburg \& van IJzendoorn, 2007; Luijk et al., 2011). Some studies also investigated whether attachment might be affected by complex interactions between an individual's genetic makeup and their experiences or exposures to certain environments, termed gene-byenvironment interactions (GxE). For example, an analysis of that same gene found that infants were more likely to be disorganised when they not only had the variant of the dopamine gene identified by Lakatos and colleagues but also had mothers who were unresolved with respect to loss (as assessed using the Adult Attachment Interview, or AAI; 
Bakermans-Kranenburg \& van IJzendoorn, 2007). Another team found a GxE effect of parental responsiveness on disorganisation in relation to a different gene- $-\mathrm{a}$ variant of the gene that codes for the serotonin transporter (known as short-form of the 5HTTLPR; Spangler, Johann, Ronai, \& Zimmermann, 2009). However, several subsequent efforts, including a large-scale investigation (Luijk et al., 2011) failed to replicate evidence from smaller studies that genes or gene-by-environment interactions are involved in attachment security or disorganisation. Overall, the implication of both the twin and candidate gene studies is that, in keeping with the predictions of attachment theory, attachment security and insecurity in early life are strongly influenced by the environment and show little evidence of being determined by genes.

Another mechanism through which genes impact child developmental outcomes is by affecting how susceptible children are to environmental intervention. Randomised control trials (RCT), where participants are randomly allocated to receive an intervention or to be placed in a control group, provide a particularly powerful opportunity to test this special case of GxE, because the researcher, or intervenor, directly introduces a change to the environment. A recent example of such research investigated whether the gene variant of the serotonin transporter mentioned above (5HTTLPR) moderated the efficacy of a homevisiting intervention designed to improve attachment in mother-infant dyads in an impoverished community in South Africa (Morgan et al., 2017). Larger intervention effects were seen for participants with one particular genetic variant. Specifically, for carriers of at least one copy of the short form of this gene, the intervention effects were significant (with $84 \%$ of infants secure in the intervention group vs. $58 \%$ secure among those not receiving intervention); in contrast, for carriers of two copies of the long form of the gene, the number who were securely attached did not differ based on whether their mothers received the 
intervention ( $71 \%$ vs. $70 \%$ secure). These results demonstrate the potential importance of genetic differences when considering the efficacy of psychosocial interventions aimed at improving developmental outcomes, such as attachment security. Put simply, some children benefit more from psychosocial intervention than others, depending on their genetic makeup.

There is strong evidence that the environment, and specifically severe neglect, is the major determinant of the more severe forms of disrupted attachment behaviour, such as those observed among children classified as having Reactive Attachment Disorder (RAD) or Disinhibited Social Engagement Disorder (DSED). The clearest evidence of this comes from the English Romanian Adoptees (ERA) study which found high rates of DSED-type behaviour in children rescued from Romanian orphanages and placed in UK adoptive families. The degree of DSED-type behaviour was highly dependent on how late in development the children were removed from the institution-for example, more than $30 \%$ of children placed in adoptive families after 18 months of age were classified as having DSED at age 6 years compared to half that rate in those placed earlier (Kreppner et al., 2010; Rutter, O'Connor \& the ERA, 2004).

Remarkably, high rates of disinhibited behaviour were observed even when the late-adoptees (in the more recent reports the definition of late adopted was age $>6$ months) were followed up at age 11, 16 and 22 years, with DSED typically also being associated with other difficulties, particularly problems with attention, cognitive function and autistic spectrum symptoms (Kennedy et al., 2017). This long-term persistence, and its marked association with the timing of placement, suggests the possibility that a sensitive period may be operating in early life (beginning somewhere between 6 and 18 months). 
Notably, even though the environment clearly plays a major role, evidence of GxE effects have also been reported in relation to signs of attachment disturbances or disorder. Specifically, in a study with institutionalised children, carriers of two copies of the short variant of the serotonin transporter gene were found to display the most disinhibited behaviour when institutionally reared (vs. family-reared), whereas for long-allele carriers the rearing experience was not associated with disinhibited behaviour (Mesquita et al., 2015). Furthermore, a RCT comparing children in institutional care to those randomised to highquality foster-care revealed that children with two short alleles of the 5-HTTLPR (and, separately, with a variant of another gene called BDNF), manifested the most disinhibited behaviour of all children if they remained institutionalised, but the least if they were randomly assigned to foster care (Drury et al., 2012). While the former study is consistent with the idea that some genes may make children more vulnerable to adverse experiences, the latter is consistent with a model of differential susceptibility (see Ellis, Boyce, Belsky, Bakermans-Kranenburg, \& van Ijzendoorn, 2011), meaning that some children may be more strongly affected by both positive and negative experiences (for better, and for worse). In either case, these studies provide evidence of GxE effects in the emergence of disinhibited social engagement behaviour.

Thus far we have reviewed work on the genetic determinants of attachment during infancy and toddlerhood. However, one cannot assume the picture will be the same through to adulthood. Indeed, that does not seem to be the case. Studies using self-reports with adult samples have been quite consistent in showing that attachment anxiety is influenced by genetic factors, and larger twin studies also tend to indicate genetic influence on attachment avoidance (e.g., Franz et al., 2011; Picardi, Fagnani, Nisticò, \& Stazi, 2011). Regarding findings from interview measures of attachment, the strongest available direct evidence 
comes from a relatively large-scale study with adolescent twins, using the Child Attachment Interview (Fearon, Shmueli-Goetz, Viding, Fonagy, \& Plomin, 2014). The results were in sharp contrast to those reviewed above from twin studies of infant/toddler attachment, showing that genes accounted for approximately $40 \%$ of the variation in attachment security, and that the shared environment played a negligible role. Further work is needed to test whether genetic influences also apply to attachment into adulthood as assessed using interviews like the AAI.

In summary, the evidence clearly shows that security and insecurity, and indeed attachment disorders, are largely determined by the environment, particularly in infancy and early childhood. This has important implications for practice, suggesting that changes in the environment (e.g. from a depriving institutional setting to good quality fostering or adoption) provide opportunities for change. There is indeed evidence that both RAD and DSED are related to the existence and degree of experiences of adverse or insufficient care (LyonsRuth, Bureau, Riley, \& Atlas-Corbett, 2009; O’Connor, Rutter, \& English and Romanian Adoptees Study Team, 2000; Oliveira, Fearon, Belsky, Fachada, \& Soares, 2015; Smyke et al., 2002), and that the introduction of changes in the environment has an impact on rates of these forms of disturbed behaviour. For example, compared to children in a standard unit in Romanian institutions, a group of children placed in a special unit that restricted the number of caregivers each child encountered in a day had significantly fewer signs of both RAD and DSED (Smyke et al., 2002). In addition, while DSED appears to be more persistent, RAD in previously institutionalised children diminishes or disappears once the child is placed in a more normative caregiving environment such as adoption or good quality foster care (e.g., Hodges \& Tizard, 1989; Smyke et al., 2012; also see Zeanah \& Gleason, 2010). 
This picture of an overwhelming predominance of environmental influences as opposed to genetic ones on attachment outcomes may well change in later childhood, adolescence or adulthood but more research is needed to establish this firmly. Common patterns of attachment security and insecurity and more severe disturbances in attachment behaviour may show genetic differential susceptibility—with some children being more susceptible to the environment or to intervention than others. Of course, the fact that genes play a limited role in attachment in young children does not mean that there is no role for biology at all. As we explore below, there is a lot of interest in understanding how the environment influences our biology and specifically in the connections between attachment and physiology and in the neural circuity of attachment.

\section{Physiology: social affiliation}

Increasing evidence indicates that human attachment and social behaviour are mediated in part by the extended oxytocinergic and vasopressin systems. This section will only review the role of oxytocin; for a review on the role of vasopressin see Carter and colleagues (2005), particularly chapters 5 and 15 .

Oxytocin (OT) is a neuro-hormone that is critically involved in regulating not only reproductive processes, but also social behaviour, such as social recognition, mother-infant attachment and pair bonding (Carter, 1998; Winslow \& Insel, 2002). In addition to having direct effects on social behaviour and attachment, the oxytocinergic system interacts with other biological systems that have important effects on behaviour, particularly those relevant for behavioural and neuroendocrine responses to social stress (Feldman, 2012). The biology of the oxytocin system appears to be very open to environmental influences (Feldman, 2012; Gunnar \& Quevedo, 2007; McCrory, De Brito, \& Viding, 2012). 
There is growing research work on OT with humans that is in line with what had been seen in animals, primarily showing an association between peripheral levels of OT (e.g., as measured from saliva samples collected with cotton swabs, or urine samples) and caregiving behaviour. In a series of studies by Feldman and colleagues (for a review see Feldman, 2012) OT was investigated in relation to attachment behaviours. Even before a child is born, increased maternal levels of OT both during pregnancy and the first post-partum month have been associated with more maternal attachment-related thoughts and behaviours with her baby, such as gaze, vocalisations, positive affect and affectionate touch, as well as attachmentrelated thoughts.

Another of these studies testing OT levels in first-time mothers and fathers in the first postpartum weeks and again six months later, found that, at both time-points, maternal and paternal levels were inter-related, which has been termed biological synchrony; furthermore, maternal OT was related to the amount of affectionate parenting behaviours, whereas paternal OT correlated with the degree of stimulatory parenting behaviours. An attachment-related behaviour that has been particularly associated with OT is touch. For example, in another study by this team, where parents interacted with their 6-month old child during a "play and touch" session, mothers who provided high levels of affectionate touch showed an increase in salivary OT from baseline to post-interaction, but such increase was not observed among mothers providing minimal touch. In turn, OT levels increased in fathers who provided high levels of stimulatory contact (e.g. throwing the infant in the air), but not those engaging in minimal stimulatory touch. OT levels have similarly been associated with the social-affective play in both mothers' and fathers', and with the degree of interactive synchrony between parent and child. Furthermore, parent and infant OT levels have been found to be inter- 
related, particularly for dyads high in synchrony. Feldman and colleagues argued that such findings suggest that behavioural synchrony provides one channel through which parental OT shapes the infant's emerging neuropeptide organisation, which then influences their subsequent social behaviour. These findings also highlight the importance of caregivers' affectionate touch for the functioning of this biological system, which in turn is implicated in parenting behaviour, with potential implications for children being raised in settings where physical touch is discouraged.

Given the association of OT with parental attachment and caregiving, it has also been studied in individuals who were reared in highly atypical or adverse conditions. Interestingly, adopted children with a history of early institutionalisation have been observed to show a reduced rise in urinary OT levels after an interactive episode with their adoptive mother, compared to children without such a history (Fries, Ziegler, Kurian, Jacoris, \& Pollak, 2005). Relatedly, histories of child abuse and neglect in adult women have been associated with lower OT concentrations in cerebrospinal fluid (Heim et al., 2009), a result that is consistent with what has been found in nursery-reared (as opposed to maternally-reared) rhesus monkeys. Furthermore, in a study in which adult men received a dose of intranasallyadministered OT, those who had experienced early parental separation showed signs of altered central sensitivity to the effects of OT. Specifically, these participants did not experience as much of a reduction in cortisol after they received OT as men without a history of parental separation (Meinlschmidt \& Heim, 2007).

Together, these studies indicate reduced OT levels and/or function in individuals with adverse early caregiving experiences. Even though these research designs do not allow inferences of causation, they do suggest that such adverse experiences may disrupt the 
normal development of the OT system, often with persisting effects. These alterations might interfere with the OT system's ability to protect the individual against stress, and may increase vulnerability to psychiatric disorders (Meinlschmidt \& Heim, 2007). It can be speculated that decreased OT availability in the organism may contribute to the transmission of maltreatment across generations (in other words, the cycle of risk), because OT is well established as an important mediator of parental behaviour (Gordon et al., 2010a; Heim et al., 2009). If the above findings are replicated in larger samples, they will have implications for clinical intervention, for example the development of therapeutics targeting the OT system to prevent and reverse the adverse outcomes of childhood adversity and promote resilience against stress (Heim et al., 2009; Meinlschmidt \& Heim, 2007).

Crucially, an investigation of foster mothers assessed their OT levels soon after the infant's placement and again three months later. Foster mothers' OT production in response to a cuddle interaction was associated with the amount of behavioural expressions of delight toward their foster infants in a play interaction at both time-points. Moreover, over time, foster mothers' OT production in response to a cuddle interaction became significantly linked to their brain activity in response to viewing an image of their foster infant. This work shows that even when biological relatedness is eliminated as a factor, OT may still be significantly implicated in the formation of an attachment relationship (Bick, Dozier, Bernard, Grasso, \& Simons, 2013).

To summarise, the literature linking oxytocin levels with affiliative and caregiving behaviour shows the plausibility of the involvement of this neuro-hormone in attachment processes. Moreover, OT has been associated with mothers' and fathers' attachment relationships throughout life: to own parents, partner, and infant, indicating that OT may be involved in an 
individual's multiple attachments across the lifespan (Feldman, Gordon, \& Zagoory-Sharon, 2011).

\section{Physiology: stress responses}

When an organism encounters a stressor, it triggers the activation of physiological systems designed to ensure its survival (Gunnar \& Quevedo, 2007). While this is an adaptive response, chronic activation of these physiological systems can be damaging for both physical and psychological health. Accordingly, a considerable body of work has been conducted to investigate how security/insecurity of attachment is related to the functioning of the stress system.

In humans, there are several ways in which physiological correlates of attachment have been studied, for example measuring heart rate or hormones involved in the stress response. We first review work on the relationship between attachment patterns and heart rate during the Strange Situation Procedure itself. Findings from a pioneer study (Sroufe \& Waters, 1977) indicated that the heart rates of secure infants—relative to both resistant and avoidant infants - decelerated most quickly when reunited with their caregiver following a brief separation; this is consistent with the idea that secure attachment behaviour allows the infant a more efficient means of regulating physiological arousal. A second finding was that avoidant infants, despite their outward demeanour, showed similar elevations in heart rate to the other attachment categories during separation; this is also consistent with the theory in supporting the view that avoidance is a secondary behavioural strategy for coping with attachment-related stress, and not an indication of a lack of distress. Even though these findings were difficult to replicate, a subsequent study did find elevated heart rate in insecure infants, particularly disorganised infants, during the final separation episode in the Strange 
Situation (Spangler \& Grossmann, 1993). Moreover, consistent with the above results for heart rate in avoidant infants, an investigation of a heart-rate marker of parasympathetic activity during the Strange Situation, namely respiratory sinus arrhythmia (RSA), showed that avoidant (compared to secure) infants had greater decreases from baseline to separation; such result suggests a greater recruitment of internal resources toward actively coping with stress (Hill-Soderlund et al., 2008).

However illuminating these findings may be, considerably more work has been done on the link between attachment and the functioning of the hypothalamic-pituitary-adrenocortical (HPA) axis, and particularly the hormone cortisol which is produced by the HPA system in response to stress (see Juster, McEwen, \& Lupien, 2010). The HPA system is a logical place to look for connections between caregiving and stress because extensive animal research shows that this system is very sensitive to environmental exposures, and affects emotion, cognition, and behaviour (Lupien, McEwen, Gunnar, \& Heim, 2009). Indeed, these animal studies suggest that the HPA axis shows sensitive periods of development during which its functioning is programmed by the quality of parental care (Gunnar \& Quevedo, 2007).

A series of studies has looked at whether attachment security and insecurity is related to how strongly children's HPA systems respond to stress, as indicated by changes in cortisol production. We first look at studies that assessed infants' salivary cortisol levels (usually sampled from cotton swabs) before and after the Strange Situation. An early investigation showed that insecure infants had greater increases in cortisol from baseline to post-Strange Situation, and that this effect was most pronounced among disorganised children (Spangler \& Grossmann, 1993). Subsequent studies found the same increased cortisol response to the Strange Situation among insecure infants, however only in those who were also rated high on 
inhibited temperament (Nachmias, Gunnar, Mangelsdorf, Parritz, \& Buss, 1996; Spangler \& Schieche, 1998). A more recent, albeit small study found that disorganised infants had a lower baseline level of cortisol than their organised counter-parts, and a greater increase in cortisol in response to the Strange Situation (Bernard \& Dozier, 2010). Another, larger, study found that it was resistant infants (and not disorganised ones) who appeared to be more reactive to the procedure, that is, they showed the largest increases in cortisol from baseline to post-Strange Situation (Luijk et al., 2010). In conclusion, there is evidence indicating that insecure children show heightened physiological responses to and/or poorer down regulation of stress, but it is not entirely clear which insecure subgroups are most affected.

Work examining this issue outside of the Strange Situation goes in the same direction. In two different studies, insecure infants who were also temperamentally inhibited showed greater cortisol responses to challenging tasks (Nachmias et al., 1996; Schieche \& Spangler, 2005). One longitudinal study found that adolescents who had been rated disorganised in infancy exhibited increased cortisol levels compared to the non-disorganised group after a feareliciting task (Spangler \& Zimmermann, 2014). In spite of this body of research showing that disorganised children may show heightened cortisol responses to a stressor, they have also been found to have a more flattened cortisol profile across the day compared to nondisorganised children (Luijk et al., 2010). Indeed, this pattern of flattened cortisol profile across the day is commonly associated with experiences of chronic stress and risk for psychological disturbance.

The evidence just reviewed thus indicates that attachment quality does impact on infants' physiological responses to the Strange Situation and to other stressors. Furthermore, the evidence suggests that temperament and possibly genetic differences are also relevant- 
security of attachment may be more important as a buffer against stress for children who are more disposed to stress in the first place (see van IJzendoorn \& Bakermans-Kranenburg, 2012).

Researchers have also investigated physiological functioning in children who have experienced more profoundly difficult experiences in relation to attachment. Work with abused and neglected children, as well as those reared in institutions or foster care, has found altered stress functioning, particularly a lack of the normal daily profile ('diurnal rhythm') of cortisol production (Carlson \& Earls, 1997; Dozier et al., 2006; McLaughlin et al., 2015).

Interestingly, two clinical trials have tested whether attachment-focused interventions can improve stress function in young children. The first was a randomised clinical trial (RCT) of an intervention called Attachment and Bio-behavioural Catch-up (ABC), focused on promoting security of attachment and in supporting the child's stress regulation through sensitive and responsive care, in a sample of young children in foster care. This intervention led to a reduction in children's basal cortisol—relative to those who were assigned a control treatment (Dozier, Peloso, Lewis, Laurenceau, \& Levine, 2008). Another RCT of a sensitivity-focused video-feedback intervention for toddlers at risk of behavioural problems replicated this result of a reduction in basal cortisol, although only among children with the variant of the dopamine D4 receptor gene referred to earlier in this article, who might be considered at risk of cortisol hyper-reactivity (Bakermans-Kranenburg, Van IJzendoorn, Pijlman, Mesman, \& Juffer, 2008). These studies provide important evidence concerning the causal role of sensitive parental care on the child's physiological functioning and show that clinical intervention can help. 


\section{Brain anatomy and functioning}

Research on attachment and the brain falls into two broad categories. The first, and largest, body of work uses neuroimaging techniques to look at how the brain processes attachmentrelevant information in adults who differ in their attachment style - using questionnaire methods or interviews like the AAI. These studies really tell us about the brain mechanisms that support caregiving and attachment behaviour in adult relationships (a parent's care for a child, or an individual's attachment functioning with their romantic/spousal partner). The second, and smaller, body of research focuses on differences in brain structure (i.e. anatomical features) and function (i.e. the neural activity) between children who have histories of secure or insecure attachment. Such studies are more directly investigating the role of early attachment experiences on brain development. There is clear evidence from animal studies that brain development is shaped by early experience, and the same is likely to be true in humans, particularly during the early years when the brain develops at its fastest rate.

The first body of research is that investigating how the brain processes information involved in adults' attachment relationships with their offspring and with romantic partners, and has found considerable evidence for a key role for brain circuits implicated in reward, arousal and motivation. Findings from structural and functional imaging studies indicate that motherhood - particularly for women with a secure attachment style and for those with more positive perceptions of their infants - is associated with increased activation, and increased grey matter volume, in regions of the brain known as the reward network, as well as other interconnected regions such as the hypothalamus or orbitofrontal cortex (Kim et al., 2010; Strathearn, Fonagy, Amico, \& Montague, 2009). In a seminal study, secure and insecure mothers were scanned while viewing their own and an unknown infant's happy and sad 
expressions (Strathearn et al., 2009). Secure mothers showed greater activations to their infant's face in the reward-region known as the ventral striatum and in oxytocin-rich hypothalamic areas. Interestingly, these activations correlated with the mother's peripheral oxytocin response to contact and interaction with her infant. In contrast, insecure-avoidant mothers showed low ventral striatum and medial orbitofrontal activation when seeing images of their own babies, and greater insular activation to their infant's sad expression. This latter brain region is associated with, amongst other things, negative emotion. The authors concluded that for securely attached (but not insecure) mothers, infant cues may act as an important rewarding and motivating signal, reinforcing responsive maternal care. In another recent study, adults with insecure attachment representations (measured by the AAI) showed heightened activation of the amygdala — a key brain structure involved in perceiving threat, negative emotions and fear conditioning — when exposed to infant crying compared to individuals with secure attachment representations (Riem, Bakermans-Kranenburg, van IJzendoorn, Out, \& Rombouts, 2012).

Studies have also found that brain regions involved in responding to threat are important in distinguishing adults whose marital/partner relationships are secure versus insecure. One fMRI study scanned women as they were subjected to the threat of mild electric shock while holding their partner's hand, that of a stranger, or no hand at all. Researchers found that when women were holding their husband's hand they showed reduced activation in multiple brain regions involved in threat, and particularly so when the marital relationship was of higher quality (Coan, Schaefer, \& Davidson, 2006). Higher relationship quality predicted greater attenuation of threat-related neural activation in the right anterior insula, superior frontal gyrus, and hypothalamus during spousal (but not stranger) hand holding. This study suggests that physical contact with the partner, and particularly within high quality relationships, helps 
to regulate threat responses in the brain. Although it has never been done, one would speculate that a similar pattern of threat-related neural deactivation would be observed in secure children when in close contact with their primary carers.

Research on the neural correlates of adults' attachment styles have reported the involvement of networks implicated in negative affect and social aversion. For example, an fMRI study of adults during a task eliciting social rejection found that avoidant attachment was associated with decreased activation in the anterior insula and dorsal anterior cingulate cortex, whereas anxious attachment was associated with heightened activity in these regions, which have previously been linked to responses to social rejection (DeWall et al., 2012). The authors interpreted these correlates as consistent with a hypervigilance to signs of rejection in anxious individuals, and with emotional withdrawal of avoidant individuals. Another study found evidence of reduced responsiveness in brain areas associated with reward in avoidant adults when they viewed happy faces, while individuals with an anxious attachment style showed heightened activation in the left amygdala (which is involved in processing social threat) in response to angry faces, suggesting an increased sensitivity to social punishment or disapproval (Vrtička, Andersson, Grandjean, Sander, \& Vuilleumier, 2008).

The second body of research, namely that looking at brain development in relation to children's attachments, is very scarce. One exception is work showing that insecurely attached infants demonstrate reduced relative left frontal brain activation compared to securely attached infants, using electroencephalography (EEG; Dawson et al., 2001; Dawson, Klinger, Panagiotides, Spieker, \& Frey, 1992). Reduced relative left frontal brain activation has been linked to negative emotional states, social withdrawal and behavioural inhibition. One other study following children longitudinally showed that early attachment insecurity 
(assessed at 18 months) was associated, at 22 years of age, with heightened activation of brain regions involved in cognitive control during a task that required young adults to upregulate their positive emotions (Moutsiana et al., 2014) - as if doing so was more difficult, and required greater mental effort than those with a history of secure attachment. In this same sample, the authors found that early insecurity was associated with larger amygdala volumes in young adulthood (Moutsiana et al., 2015). These studies show that early attachment quality has measurable effects on neural organisation and brain anatomy, which may persist into the adult years.

A different tack that researchers have taken to studying the impact of early experiences on brain development is via analysis of variations in caregiving (as opposed to attachment per se). For example, infants of mothers who were rated as low in responsiveness during observed mother-infant interactions exhibit greater right frontal EEG activation associated with negative emotionality and inhibition (Hane \& Fox, 2006). In another study, infants of mothers who were more sensitive and responsive during their interactions showed larger EEG neural responses to happy faces, relative to neutral faces (Taylor-Colls \& Fearon, 2015). This finding suggests that sensitive parental responses to the infant's cues during interactions lead the developing brain to encode or evaluate positive emotional signals differently, perhaps attaching greater motivational value to them. The authors highlighted that this finding is intriguing given the crucial role of positive emotional expressions in eliciting and reinforcing approach behaviour, social engagement, and social reward.

A number of studies have also looked at brain function in children who have experienced severe neglect as a result of institutional rearing. EEG/ERP studies have consistently found that institutionalised children, when compared to age-mates raised continuously in their birth 
families, show signs of a pervasive cortical hypoactivation (e.g., Marshall, Fox, \& BEIP core group, 2004; Moulson, Westerlund, Fox, Zeanah, \& Nelson, 2009). These findings are consistent with structural brain imaging studies, which show that institutionally reared children have reduced overall white and grey matter volumes compared to comparison controls (Mehta et al., 2009; Sheridan, Fox, Zeanah, McLaughlin, \& Nelson, 2012). What is encouraging is that children randomised to good quality foster-care had greater white matter volumes relative to those who remained in institutions, suggesting potential for developmental "catch-up" in white matter growth (Sheridan et al., 2012). Children raised in institutions have also been found to show reduced reward-related brain activation (e.g., Goff et al., 2013) and heightened amygdala activation to faces (Tottenham et al., 2011), as well as enlarged amygdala volumes (Mehta et al., 2009). Recall that the amygdala is a brain region that supports emotion processing, and enlarged or heightened amygdala activity tends to be associated with increased emotional reactivity and social-emotional difficulties. Therefore it is plausible that brain alterations in regions highly sensitive to early life rearing conditions, such as the amygdala (cf. Tottenham et al., 2011), partly underlie institutionalised children's social and emotional difficulties.

It is also notable that some evidence is emerging that the behaviours associated with DSED, which is commonly observed in institutionally reared children, may have distinct brain correlates. Institutionally-reared children with disinhibited behaviour have been reported to show increased low-frequency/ decreased high-frequency EEG power (Tarullo, Garvin, \& Gunnar, 2011), as well as lack of distinction in ERP responses between the face of their caregiver and an unfamiliar person (Mesquita et al., 2015). Moreover, an fMRI study reported that post-institutionalised children and youth showed little amygdala discrimination between mother and stranger stimuli, in contrast to the clear discrimination seen in controls 
(Olsavsky et al., 2013). Crucially, the reduced amygdala differentiation (of mother versus stranger) among the institutionalised children was correlated with their reported disinhibited behaviour, which is consistent with the ERP results described above.

The study of brain development in children exposed to institutional rearing assumes that, when developing in such a neglectful environment, the young child's nervous system lacks input that would be "expectable" in one's rearing environment — such as access to a consistent caregiver and appropriate cognitive and emotional stimulation. This absence of the most basic level of social stimulation is hypothesised to negatively affect the development of neural networks, for example via excessive retraction of neurons and synapses (Nelson, 2007; Pechtel \& Pizzagalli, 2011). In addition, institutional rearing has been associated with dysregulation of other physiological systems as seen earlier in this review, which are themselves associated with brain development (cf. Nelson, Bos, Gunnar, \& Sonuga-Barke, 2011). Such a body of work affords, then, the opportunity to uncover possible mechanisms through which early care experiences impact on brain development, and the extent to which the brain remains "plastic" throughout the life course.

It is unclear how much findings from institutionalised samples apply to children being raised in foster families. This is further complicated by the great variability in the quality of care and stability or disruptions in care seen in both of these settings, which may be as important as the type of care as such (see Woodhouse, Miah, \& Rutter, 2018). Nevertheless, we believe that there are several important points of connection between the literature on institutional care and foster care. Firstly, we know that children raised in institutions are at heightened risk of experiencing both disorganised attachment and attachment disorders (DSED and RAD), and we would expect the consequences of these and their underlying neurobiology to be 
similar in the foster care context, even though direct comparative studies have never been done. We also know that both populations have often been exposed to highly adverse early rearing experiences (including separation from attachment figures and maltreatment), whose negative effects are relatively well documented and consistent, both in terms of socioemotional outcomes and neurodevelopment (McCrory, Gerin, \& Viding, 2017). It is highly likely that some of the emotional difficulties and neurobiological correlates of these that are observed among children in foster and institutional care are similar and relate to their exposure to maltreatment. Nevertheless, clear differences also exist in the adverse outcomes associated with maltreatment and institutional rearing, which must be kept in mind, and direct comparisons between children's attachment outcomes in each type of setting will always be uncertain until rigorous research comparing them has been undertaken.

\section{Conclusion}

In this review, we have provided an inevitably selective summary of the literature on the biological aspects of attachment. Attachment represents a crucial evolutionarily adapted behavioural system for ensuring children's protection and survival, and evidence from biologically-inspired studies shows a number of consistent things that enhance our understanding of this key aspect of child development.

First, genetic studies show quite clearly that variation in secure or insecure attachment in early life is largely caused by the environment. There is also clear evidence that more severe disturbances in attachment-related behaviour, such as those captured by the diagnostic categories RAD and DSED are also strongly influenced by the environment, in this case by severe early-life neglect. Disinhibited behaviour, but not RAD or more normative attachment patterns, may represent the impact of early neglect on a sensitive window of brain 
development, which in turn causes quite persistent changes in social behaviour, even into adulthood. Genes may play a small role in attachment insecurity and in attachment disorders, but primarily as vulnerability factors or factors that affect children's susceptibility to psychosocial intervention.

Insecure attachment is also associated with differences in stress physiology, although not strongly or consistently across all studies. Stress dysregulation is quite consistently observed in children who have experienced more severe attachment adversity, such as those raised in institutions.

Finally, we are beginning to understand more about the brain basis of attachment. Of course, the complexity of the attachment behavioural system means that it would be impossible to locate a single, dedicated attachment circuit—-"a bit like trying to find the real artichoke by peeling away all its leaves" (Coan, 2008, p. 3). Rather, neuroimaging techniques allow us to study the mechanisms involved in the operation of this complex behavioural system. Important progress has been made in this field. The brain's reward circuits appear to be particularly important in mediating parental caregiving, whereas brain areas related to emotion and emotional regulation appear to be linked to the child's attachment security. Children who have experienced severe neglect show quite widespread changes in both the structure and function of the brain, and it is currently unclear how reversible these might be.

However, there is already some encouraging research pointing to the remedial effects of high quality caregiving following deprivation (Bernard et al., 2012; Sheridan et al., 2012; Smyke et al., 2012; The St. Petersburg-USA Orphanage Research Team, 2008), suggesting that our best chance of intervening with children who have been exposed to poor caregiving 
environments (when prevention has failed) is by improving their current environmentswhere they receive consistent, dedicated and sensitive caregiving, as earlier in life as possible. 


\section{References}

American Psychiatric Association. (2013). Diagnostic and statistical manual of mental health disorders: DSM-5 (5th ed.). Washington, DC: American Psychiatric Publishing.

Bakermans-Kranenburg, M. J., \& van IJzendoorn, M. H. (2007). Research Review: Genetic vulnerability or differential susceptibility in child development: the case of attachment. Journal of Child Psychology and Psychiatry, 48(12), 1160-1173. https://doi.org/10.1111/j.1469-7610.2007.01801.x

Bakermans-Kranenburg, M. J., Van IJzendoorn, M. H., Pijlman, F. T. A., Mesman, J., \& Juffer, F. (2008). Experimental evidence for differential susceptibility: Dopamine D4 receptor polymorphism (DRD4 VNTR) moderates intervention effects on toddlers' externalizing behavior in a randomized controlled trial. Developmental Psychology, 44(1), 293-300. https://doi.org/10.1037/0012-1649.44.1.293

Belsky, J. (1996). Parent, infant, and social-contextual antecedents of father-son attachment security. Developmental Psychology, 32(5), 905-913. https://doi.org/10.1037/00121649.32.5.905

Bernard, K., \& Dozier, M. (2010). Examining infants' cortisol responses to laboratory tasks among children varying in attachment disorganization: Stress reactivity or return to baseline? Developmental Psychology, 46(6), 1771-1778. https://doi.org/10.1037/a0020660

Bernard, K., Dozier, M., Bick, J., Lewis-Morrarty, E., Lindhiem, O., \& Carlson, E. (2012). Enhancing attachment organization among maltreated children: Results of a randomized clinical trial. Child Development, 83(2), 623-636.

Bick, J., Dozier, M., Bernard, K., Grasso, D., \& Simons, R. (2013). Foster mother-infant bonding: Associations between foster mothers' oxytocin production, electrophysiological brain activity, feelings of commitment, and caregiving quality. Child Development, 84(3), 826-840. https://doi.org/10.1111/cdev.12008

Boris, N. W., \& Zeanah, C. H. (1999). Disturbances and disorders of attachment in infancy: An overview. Infant Mental Health Journal, 20, 1-9.

Bowlby, J. (1969). Attachment and loss, Vol. 1 Attachment. New York: Basic Books.

Bowlby, J. (1973). Attachment and loss, Vol. 2. Separation: Anxiety and anger. New York: Basic Books.

Bowlby, J. (1980). Attachment and loss, Vol. 3. Loss: Sadness and depression. New York: Basic Books. 
Carlson, M., \& Earls, F. (1997). Psychological and neuroendocrinological sequelae of early social deprivation in institutionalized children in Romania. Annals of the New York Academy of Sciences, 807(1 Integrative N), 419-428. https://doi.org/10.1111/j.17496632.1997.tb51936.x

Carter, C. S., Ahnert, L., Grossmann, K. E., Lamb, M. E., Hrdy, S. B., Porges, S. W., \& Sachser, N. (2005). Attachment and bonding: A new synthesis (Vol. 92). Mit Press.

Carter, S. (1998). Neuroendocrine perspectives on social attachment and love. Psychoneuroendocrinology, 23(8), 779-818. https://doi.org/10.1016/S03064530(98)00055-9

Coan, J. A. (2008). Toward a neuroscience of attachment. Handbook of Attachment: Theory, Research, and Clinical Applications, 2, 241-265.

Coan, J. A., Schaefer, H. S., \& Davidson, R. J. (2006). Lending a hand: Social regulation of the neural response to threat. Psychological Science, 17(12), 1032-1039. https://doi.org/10.1111/j.1467-9280.2006.01832.x

Crockenberg, S. B. (1981). Infant Irritability, mother responsiveness, and social support Influences on the security of infant-mother attachment. Child Development, 52(3), 857. https://doi.org/10.2307/1129087

Dawson, G., Ashman, S. B., Hessl, D., Spieker, S., Frey, K., Panagiotides, H., \& Embry, L. (2001). Autonomic and brain electrical activity in securely- and insecurely-attached infants of depressed mothers. Infant Behavior and Development, 24(2), 135-149. https://doi.org/10.1016/S0163-6383(01)00075-3

Dawson, G., Klinger, L. G., Panagiotides, H., Spieker, S., \& Frey, K. (1992). Infants of mothers with depressive symptoms: Electroencephalographic and behavioral findings related to attachment status. Development and Psychopathology, 4(1), 67. https://doi.org/10.1017/S0954579400005563

DeWall, C. N., Masten, C. L., Powell, C., Combs, D., Schurtz, D. R., \& Eisenberger, N. I. (2012). Do neural responses to rejection depend on attachment style? An fMRI study. Social Cognitive and Affective Neuroscience, 7(2), 184-192. https://doi.org/10.1093/scan/nsq107

Dozier, M., Manni, M., Gordon, M. K., Peloso, E., Gunnar, M. R., Stovall-McClough, K. C., ... Levine, S. (2006). Foster children's diurnal production of cortisol: An exploratory study. Child Maltreatment, 11(2), 189-197. https://doi.org/10.1177/1077559505285779

Dozier, M., Peloso, E., Lewis, E., Laurenceau, J.-P., \& Levine, S. (2008). Effects of an 
attachment-based intervention on the cortisol production of infants and toddlers in foster care. Development and Psychopathology, 20(3).

https://doi.org/10.1017/S0954579408000400

Drury, S. S., Gleason, M. M., Theall, K. P., Smyke, A. T., Nelson, C. A., Fox, N. A., \& Zeanah, C. H. (2012). Genetic sensitivity to the caregiving context: The influence of 5httlpr and BDNF val66met on indiscriminate social behavior. Physiology \& Behavior, 106(5), 728-735. https://doi.org/10.1016/j.physbeh.2011.11.014

Ellis, B. J., Boyce, W. T., Belsky, J., Bakermans-Kranenburg, M. J., \& van Ijzendoorn, M. H. (2011). Differential susceptibility to the environment: An evolutionaryneurodevelopmental theory. Development and Psychopathology, 23(1), 7-28. https://doi.org/10.1017/S0954579410000611

Fearon, P., Shmueli-Goetz, Y., Viding, E., Fonagy, P., \& Plomin, R. (2014). Genetic and environmental influences on adolescent attachment. Journal of Child Psychology and Psychiatry, 55(9), 1033-1041. https://doi.org/10.1111/jcpp.12171

Fearon, R. M. P., Van IJzendoorn, M. H., Fonagy, P., Bakermans-Kranenburg, M. J., Schuengel, C., \& Bokhorst, C. L. (2006). In search of shared and nonshared environmental factors in security of attachment: A behavior-genetic study of the association between sensitivity and attachment security. Developmental Psychology, 42(6), 1026-1040. https://doi.org/10.1037/0012-1649.42.6.1026

Feldman, R. (2012). Oxytocin and social affiliation in humans. Hormones and Behavior, 61(3), 380-391. https://doi.org/10.1016/j.yhbeh.2012.01.008

Feldman, R., Gordon, I., \& Zagoory-Sharon, O. (2011). Maternal and paternal plasma, salivary, and urinary oxytocin and parent-infant synchrony: Considering stress and affiliation components of human bonding. Developmental Science, 14(4), 752-761. https://doi.org/10.1111/j.1467-7687.2010.01021.x

Fraley, R. C., Brumbaugh, C. C., \& Marks, M. J. (2005). The Evolution and Function of Adult Attachment: A Comparative and Phylogenetic Analysis. Journal of Personality and Social Psychology, 89(5), 731-746. https://doi.org/10.1037/0022-3514.89.5.751

Franz, C. E., York, T. P., Eaves, L. J., Prom-Wormley, E., Jacobson, K. C., Lyons, M. J., ... Kremen, W. S. (2011). Adult romantic attachment, negative emotionality, and depressive symptoms in middle aged men: A multivariate genetic analysis. Behavior Genetics, 41(4), 488-498. https://doi.org/10.1007/s10519-010-9428-Z

Fries, A. B. W., Ziegler, T. E., Kurian, J. R., Jacoris, S., \& Pollak, S. D. (2005). Early experience in humans is associated with changes in neuropeptides critical for 
regulating social behavior. Proceedings of the National Academy of Sciences, 102(47), 17237-17240. https://doi.org/10.1073/pnas.0504767102

Gleason, M. M., Fox, N. A., Drury, S., Smyke, A., Egger, H. L., Nelson, C. A., \& Zeanah, C. H. (2011). Validity of evidence-derived criteria for reactive attachment disorder: Indiscriminately social/disinhibited and emotionally withdrawn/inhibited types. Journal of the American Academy of Child \& Adolescent Psychiatry, 50(3), 216-231. Goff, B., Gee, D. G., Telzer, E. H., Humphreys, K. L., Gabard-Durnam, L., Flannery, J., \& Tottenham, N. (2013). Reduced nucleus accumbens reactivity and adolescent depression following early-life stress. Neuroscience, 249, 129-138. https://doi.org/10.1016/j.neuroscience.2012.12.010

Goldsmith, H. H., \& Alansky, J. A. (1987). Maternal and infant temperamental predictors of attachment: A meta-analytic review. Journal of Consulting and Clinical Psychology, 55(6), 805-816. https://doi.org/10.1037/0022-006X.55.6.805

Gordon, I., Zagoory-Sharon, O., Leckman, J. F., \& Feldman, R. (2010a). Oxytocin and the development of parenting in humans. Biological Psychiatry, 68(4), 377-382. https://doi.org/10.1016/j.biopsych.2010.02.005

Groh, A. M., Narayan, A. J., Bakermans-Kranenburg, M. J., Roisman, G. I., Vaughn, B. E., Fearon, R. M. P., \& van IJzendoorn, M. H. (2017). Attachment and temperament in the early life course: A meta-analytic review. Child Development, 88(3), 770-795. https://doi.org/10.1111/cdev.12677

Gunnar, M., \& Quevedo, K. (2007). The neurobiology of stress and development. Annual Review of Psychology, 58(1), 145-173. https://doi.org/10.1146/annurev.psych.58.110405.085605

Hane, A. A., \& Fox, N. A. (2006). Ordinary variations in maternal caregiving influence human infants' stress reactivity. Psychological Science, 17(6), 550-556. https://doi.org/10.1111/j.1467-9280.2006.01742.x

Heim, C., Young, L. J., Newport, D. J., Mletzko, T., Miller, A. H., \& Nemeroff, C. B. (2009). Lower CSF oxytocin concentrations in women with a history of childhood abuse. Molecular Psychiatry, 14(10), 954-958. https://doi.org/10.1038/mp.2008.112

Hill-Soderlund, A. L., Mills-Koonce, W. R., Propper, C., Calkins, S. D., Granger, D. A., Moore, G. A., ... Cox, M. J. (2008). Parasympathetic and sympathetic responses to the strange situation in infants and mothers from avoidant and securely attached dyads. Developmental Psychobiology, 50(4), 361-376. https://doi.org/10.1002/dev.20302 
Hodges, J., \& Tizard, B. (1989). Social and family relationships of ex-institutional adolescents. Journal of Child Psychology and Psychiatry, 30(1), 77-97.

Juster, R.-P., McEwen, B. S., \& Lupien, S. J. (2010). Allostatic load biomarkers of chronic stress and impact on health and cognition. Neuroscience \& Biobehavioral Reviews, 35(1), 2-16. https://doi.org/10.1016/j.neubiorev.2009.10.002

Kagan, J., Snidman, N., Arcus, D., \& Reznick, J. S. (1994). Galen's prophecy: Temperament in human nature. New York, NY: Basic Books, US.

Kennedy, M., Kreppner, J., Knights, N., Kumsta, R., Maughan, B., Golm, D., ... SonugaBarke, E. (2017). Adult disinhibited social engagement in adoptees exposed to extreme institutional deprivation: examination of its clinical status and functional impact. The British Journal of Psychiatry. https://doi.org/10.1192/bjp.bp.117.200618

Kim, P., Leckman, J. F., Mayes, L. C., Feldman, R., Wang, X., \& Swain, J. E. (2010). The plasticity of human maternal brain: Longitudinal changes in brain anatomy during the early postpartum period. Behavioral Neuroscience, 124(5), 695-700. https://doi.org/10.1037/a0020884

Kreppner, J., Kumsta, R., Rutter, M., Beckett, C., Castle, J., Stevens, S., \& Sonuga-Barke, E. J. (2010). IV. Developmental course of deprivation-specific psychological patterns: Early manifestations, persistence to age 15, and clinical features. Monographs of the Society for Research in Child Development, 75(1), 79-101. https://doi.org/10.1111/j.1540-5834.2010.00551.x

Lakatos, K., Nemoda, Z., Toth, I., Ronai, Z., Ney, K., Sasvari- Szekely, M., \& Gervai, J. (2002). Further evidence for the role of the dopamine D4 receptor (DRD4) gene in attachment disorganization: interaction of the exon III 48-bp repeat and the $-521 \mathrm{C} / \mathrm{T}$ promoter polymorphisms. Molecular Psychiatry, 7(1), 27-31. https://doi.org/10.1038/sj/mp/4000986

Lakatos, K., Toth, I., Nemoda, Z., Ney, K., Sasvari-Szekely, M., \& Gervai, J. (2000). Dopamine D4 receptor (DRD4) gene polymorphism is associated with attachment disorganization in infants. Molecular Psychiatry, 5(6), 633-637.

Luijk, M. P. C. M., Roisman, G. I., Haltigan, J. D., Tiemeier, H., Booth-LaForce, C., van IJzendoorn, M. H., ... Bakermans-Kranenburg, M. J. (2011). Dopaminergic, serotonergic, and oxytonergic candidate genes associated with infant attachment security and disorganization? In search of main and interaction effects: Attachment genes? Journal of Child Psychology and Psychiatry, 52(12), 1295-1307. https://doi.org/10.1111/j.1469-7610.2011.02440.x 
Luijk, M. P. C. M., Saridjan, N., Tharner, A., van IJzendoorn, M. H., BakermansKranenburg, M. J., Jaddoe, V. W. V., ... Tiemeier, H. (2010). Attachment, depression, and cortisol: Deviant patterns in insecure-resistant and disorganized infants. Developmental Psychobiology, 52(5), 441-452. https://doi.org/10.1002/dev.20446

Lupien, S. J., McEwen, B. S., Gunnar, M. R., \& Heim, C. (2009). Effects of stress throughout the lifespan on the brain, behaviour and cognition. Nature Reviews Neuroscience, 10(6), 434-445. https://doi.org/10.1038/nrn2639

Lyons-Ruth, K., Bureau, J., Riley, C., \& Atlas-Corbett, A. (2009). Socially indiscriminate attachment behavior in the Strange Situation: Convergent and discriminant validity in relation to caregiving risk, behavior problems, and attachment insecurity. Development and Psychopathology, 21, 355-372.

Mangelsdorf, S., Gunnar, M., Kestenbaum, R., Lang, S., \& Andreas, D. (1990). Infant proneness-to-distress temperament, maternal personality, and mother-infant attachment: Associations and goodness of fit. Child Development, 61(3), 820-831.

Marshall, P. J., Fox, N. A., \& BEIP core group. (2004). A comparison of the electroencephalogram between institutionalized and community children in Romania. Journal of Cognitive Neuroscience, 16(8), 1327-1338. https://doi.org/10.1162/0898929042304723

McCrory, E. J., Gerin, M. I., \& Viding, E. (2017). Annual research review: childhood maltreatment, latent vulnerability and the shift to preventative psychiatry-the contribution of functional brain imaging. Journal of Child Psychology and Psychiatry, 58(4), 338-357.

McCrory, E., De Brito, S. A., \& Viding, E. (2012). The link between child abuse and psychopathology: A review of neurobiological and genetic research. Journal of the Royal Society of Medicine, 105(4), 151-156. https://doi.org/10.1258/jrsm.2011.110222

McLaughlin, K. A., Sheridan, M. A., Tibu, F., Fox, N. A., Zeanah, C. H., \& Nelson, C. A. (2015). Causal effects of the early caregiving environment on development of stress response systems in children. Proceedings of the National Academy of Sciences, 112(18), 5637-5642. https://doi.org/10.1073/pnas.1423363112

Mehta, M. A., Golembo, N. I., Nosarti, C., Colvert, E., Mota, A., Williams, S. C. R., ... Sonuga-Barke, E. J. S. (2009). Amygdala, hippocampal and corpus callosum size following severe early institutional deprivation: The English and Romanian Adoptees 
Study Pilot. Journal of Child Psychology and Psychiatry, 50(8), 943-951. https://doi.org/10.1111/j.1469-7610.2009.02084.x

Meinlschmidt, G., \& Heim, C. (2007). Sensitivity to intranasal oxytocin in adult men with early parental separation. Biological Psychiatry, 61(9), 1109-1111. https://doi.org/10.1016/j.biopsych.2006.09.007

Mesquita, A. R., Belsky, J., Crego, A., Fachada, I., Oliveira, P., Sampaio, A., \& Soares, I. (2015). Neural correlates of face familiarity in institutionally reared children with distinctive, atypical social behavior. Child Development, 86(4), 1262-1271. https://doi.org/10.1111/cdev.12371

Mesquita, A. R., Belsky, J., Li, Z., Baptista, J., Carvalho-Correia, E., Maciel, P., \& Soares, I. (2015). Institutionalization and indiscriminate social behavior: Differentialsusceptibility versus diathesis-stress models for the 5-HTTLPR and BDNF genotypes. Physiology \& Behavior, 152, 85-91. https://doi.org/10.1016/j.physbeh.2015.09.015

Morgan, B., Kumsta, R., Fearon, P., Moser, D., Skeen, S., Cooper, P., ... Tomlinson, M. (2017). Serotonin transporter gene (SLC6A4) polymorphism and susceptibility to a home-visiting maternal-infant attachment intervention delivered by community health workers in South Africa: Reanalysis of a randomized controlled trial. PLOS Medicine, 14(2), e1002237. https://doi.org/10.1371/journal.pmed.1002237

Moulson, M. C., Westerlund, A., Fox, N. A., Zeanah, C. H., \& Nelson, C. A. (2009). The effects of early experience on face recognition: An event-related potential study of institutionalized children in Romania. Child Development, 80(4), 1039-1056. https://doi.org/10.1111/j.1467-8624.2009.01315.x

Moutsiana, C., Fearon, P., Murray, L., Cooper, P., Goodyer, I., Johnstone, T., \& Halligan, S. (2014). Making an effort to feel positive: insecure attachment in infancy predicts the neural underpinnings of emotion regulation in adulthood. Journal of Child Psychology and Psychiatry, 55(9), 999-1008. https://doi.org/10.1111/jcpp.12198

Moutsiana, C., Johnstone, T., Murray, L., Fearon, P., Cooper, P. J., Pliatsikas, C., ... Halligan, S. L. (2015). Insecure attachment during infancy predicts greater amygdala volumes in early adulthood. Journal of Child Psychology and Psychiatry, 56(5), 540548. https://doi.org/10.1111/jcpp.12317

Nachmias, M., Gunnar, M., Mangelsdorf, S., Parritz, R. H., \& Buss, K. (1996). Behavioral inhibition and stress reactivity: The moderating role of attachment security. Child Development, 67(2), 508. https://doi.org/10.2307/1131829

Nelson, C. A. (2007). A neurobiological perspective on early human deprivation. Child 
Development Perspectives, 1(1), 13-18. https://doi.org/10.1111/j.17508606.2007.00004.x

Nelson, C. A., Bos, K., Gunnar, M. R., \& Sonuga-Barke, E. J. S. (2011). V. The neurobiological toll of early human deprivation. Monographs of the Society for Research in Child Development, 76(4), 127-146. https://doi.org/10.1111/j.15405834.2011.00630.x

O'Connor, T. G., \& Croft, C. M. (2001). A twin study of attachment in preschool children. Child Development, 72(5), 1501-1511. https://doi.org/10.1111/1467-8624.00362

O’Connor, T. G., Rutter, M., \& English and Romanian Adoptees Study Team. (2000). Attachment disorder behavior following early severe deprivation: Extension and longitudinal follow-up. Journal of the American Academy of Child \& Adolescent Psychiatry, 39(6), 703-712.

Oliveira, P. S., Fearon, R. P., Belsky, J., Fachada, I., \& Soares, I. (2015). Quality of institutional care and early childhood development. International Journal of Behavioral Development., 39(2), 161-170.

Olsavsky, A. K., Telzer, E. H., Shapiro, M., Humphreys, K. L., Flannery, J., Goff, B., \& Tottenham, N. (2013). Indiscriminate amygdala response to mothers and strangers after early maternal deprivation. Biological Psychiatry, 74(11), 853-860. https://doi.org/10.1016/j.biopsych.2013.05.025

Oosterman, M., \& Schuengel, C. (2008). Attachment in foster children associated with caregivers' sensitivity and behavioral problems. Infant Mental Health Journal, 29, $609-623$.

Pechtel, P., \& Pizzagalli, D. A. (2011). Effects of early life stress on cognitive and affective function: an integrated review of human literature. Psychopharmacology, 214(1), 5570. https://doi.org/10.1007/s00213-010-2009-2

Picardi, A., Fagnani, C., Nisticò, L., \& Stazi, M. A. (2011). A twin study of attachment style in young adults: A twin study of adult attachment style. Journal of Personality, 79(5), 965-992. https://doi.org/10.1111/j.1467-6494.2010.00707.x

Riem, M. M. E., Bakermans-Kranenburg, M. J., van IJzendoorn, M. H., Out, D., \& Rombouts, S. A. R. B. (2012). Attachment in the brain: adult attachment representations predict amygdala and behavioral responses to infant crying. Attachment \& Human Development, 14(6), 533-551. https://doi.org/10.1080/14616734.2012.727252

Roisman, G. I., \& Fraley, R. C. (2008). A behavior-genetic study of parenting quality, infant 
attachment security, and their covariation in a nationally representative sample. Developmental Psychology, 44(3), 831-839. https://doi.org/10.1037/00121649.44.3.831

Rutter, M., Kreppner, J., \& Sonuga-Barke, E. (2009). Emanuel Miller Lecture: Attachment insecurity, disinhibited attachment, and attachment disorders: Where do research findings leave the concepts? Journal of Child Psychology and Psychiatry, 50, 529543.

Rutter, M., \& O'Connor, T. G. (2004). Are there biological programming effects for psychological development? Findings from a study of Romanian adoptees. Developmental psychology, 40(1), 81 .

Schieche, M., \& Spangler, G. (2005). Individual differences in biobehavioral organization during problem-solving in toddlers: The influence of maternal behavior, infant-mother attachment, and behavioral inhibition on the attachment-exploration balance. Developmental Psychobiology, 46(4), 293-306. https://doi.org/10.1002/dev.20065

Sheridan, M. A., Fox, N. A., Zeanah, C. H., McLaughlin, K. A., \& Nelson, C. A. (2012). Variation in neural development as a result of exposure to institutionalization early in childhood. Proceedings of the National Academy of Sciences, 109(32), 12927-12932. https://doi.org/10.1073/pnas.1200041109

Simpson, J. A., \& Belsky, J. (2008). Attachment theory within a modern evolutionary framework. In Handbook of attachment: Theory, research, and clinical applications (2nd ed., pp. 131-157). New York, NY: Guilford Press; US.

Smyke, A. T., Zeanah, C. H., Gleason, M. M., Drury, S. S., Fox, N. A., Nelson, C. A., \& Guthrie, D. (2012). A randomized controlled trial comparing foster care and institutional care for children with signs of reactive attachment disorder. American Journal of Psychiatry, 169(5), 508-514.

Smyke, A., Dumitrescu, A., \& Zeanah, C. (2002). Attachment disturbances in young children I: The continuum of caretaking casualty. Journal of the American Academy of Child and Adolescent Psychiatry, 41, 972-982.

Spangler, G., \& Grossmann, K. E. (1993). Biobehavioral organization in securely and insecurely attached infants. Child Development, 64(5), 1439. https://doi.org/10.2307/1131544

Spangler, G., \& Schieche, M. (1998). Emotional and adrenocortical responses of infants to the strange situation: The differential function of emotional expression. International Journal of Behavioral Development, 22(4), 681-706. 
https://doi.org/10.1080/016502598384126

Spangler, G., \& Zimmermann, P. (2014). Emotional and adrenocortical regulation in early adolescence: Prediction by attachment security and disorganization in infancy. International Journal of Behavioral Development, 38(2), 142-154. https://doi.org/10.1177/0165025414520808

Spangler, G., Johann, M., Ronai, Z., \& Zimmermann, P. (2009). Genetic and environmental influence on attachment disorganization. Journal of Child Psychology and Psychiatry, 50(8), 952-961. https://doi.org/10.1111/j.1469-7610.2008.02054.x

Sroufe, L. A., \& Waters, E. (1977). Attachment as an organizational construct. Child Development, 48(4), 1184. https://doi.org/10.2307/1128475

Strathearn, L., Fonagy, P., Amico, J., \& Montague, P. R. (2009). Adult attachment predicts maternal brain and oxytocin response to infant cues. Neuropsychopharmacology, 34(13), 2655-2666. https://doi.org/10.1038/npp.2009.103

Tarullo, A. R., Garvin, M. C., \& Gunnar, M. R. (2011). Atypical EEG power correlates with indiscriminately friendly behavior in internationally adopted children. Developmental Psychology, 47(2), 417-431. https://doi.org/10.1037/a0021363

Taylor-Colls, S., \& Pasco Fearon, R. M. (2015). The effects of parental behavior on infants' neural processing of emotion expressions. Child Development, 86(3), 877-888. https://doi.org/10.1111/cdev.12348

The St. Petersburg-USA Orphanage Research Team. (2008). The effects of early socialemotional and relationship experience on the development of young orphanage children. In Monographs of the Society for Research in Child Development. (Vol. 3, p. vii-295).

Tottenham, N., Hare, T. A., Millner, A., Gilhooly, T., Zevin, J. D., \& Casey, B. J. (2011). Elevated amygdala response to faces following early deprivation: Neurodevelopment and adversity. Developmental Science, 14(2), 190-204. https://doi.org/10.1111/j.1467-7687.2010.00971.x

van den Boom, D. (1994). The influence of temperament and mothering on attachment and exploration: An experimental manipulation of sensitive responsiveness among lowerclass mothers with irritable infants. Child Development, 65(5), 1457-1477. https://doi.org/10.1111/j.1467-8624.1994.tb00829.x

van IJzendoorn, M. H., \& Bakermans-Kranenburg, M. J. (2012). Integrating temperament and attachment: The differential susceptibility paradigm. In Handbook of temperament (pp. 403-424). New York, NY: Guilford Press, US. 
Vaughn, B. E., Bost, K. K., \& van IJzendoorn, M. H. (2008). Attachment and temperament: Additive and interactive influences on behavior, affect, and cognition during infancy and childhood. In Handbook of attachment: Theory, research, and clinical applications (2nd ed., pp. 192-216). New York, NY: Guilford Press, US.

Vrtička, P., Andersson, F., Grandjean, D., Sander, D., \& Vuilleumier, P. (2008). Individual attachment style modulates human amygdala and striatum activation during social appraisal. PLoS ONE, 3(8), e2868. https://doi.org/10.1371/journal.pone.0002868

Winslow, J. T., \& Insel, T. R. (2002). The social deficits of the oxytocin knockout mouse. Neuropeptides, 36(2-3), 221-229. https://doi.org/10.1054/npep.2002.0909

Woodhouse, S., Miah, A., \& Rutter, M. (2018). A new look at the supposed risks of early institutional rearing. Psychological Medicine, 48(1), 1-10.

Zeanah, C. H., \& Gleason, M. M. (2010). Reactive attachment disorder: A review for DSMV. Report Presented to the American Psychiatric Association.

Paula Oliveira is a Research associate at UCL, at the Research Department of Clinical, Educational and Health Psychology.

Pasco Fearon is Chair in Developmental Psychopathology at the UCL Research Department of Clinical, Educational and Health Psychology. 